\title{
PENGEMBANGAN MEDIA PEMBELAJARAN BERBASIS ICT PADA SUBTEMA BERSYUKUR ATAS KEBERAGAMAN UNTUK SISWA KELAS IV SEKOLAH DASAR
}

\author{
Lina Novita $^{\left.a^{*}\right)}$, Tustiyana Windiyani ${ }^{a}$, Rifa Fazriani $^{*}$ ) \\ a) Universitas Pakuan, Bogor, Indonesia \\ *) e-mail korespondensi : linovtaz@gmail.com
}

Riwayat Artikel : diterima: 20 Juli 2019; direvisi: 26 Juli 2019; disetujui: 26 Agustus 2019

\begin{abstract}
Abstrak. Penelitian ini menggunakan prosedur pengembangan yang menghasilkan desain produk final berupa pengembangan media pembelajaran berbasis ICT dengan menggunakan Powerpoint interaktif. Produk ini peneliti kembangkan dengan menggabungkan langkah-langkah penelitian dari Borg and Gall dan model ASSURE. Produk yang dikembangkan dalam penelitian ini yaitu media pembelajaran berbasis ICT mengacu kurikulum 2013 untuk siswa kelas IV Sekolah Dasar. Berdasarkan langkah-langkah prosedur pengembangan di atas peneliti hanya membatasi pada 5 langkah prosedur pengembangan, yaitu (1) potensi dan masalah, (2) pengumpulan data, (3) desain produk, (4) validasi ahli, dan (5) revisi desai. Hal ini dikarenakan terbatasnya waktu yang dibutuhkan dalam penelitian dan media pembelajaran berbasis ICT ini dibuat untuk menjadi pegangan guru sehingga cukup divalidasi oleh empat guru kelas IV SD yang membuat media pembelajaran berbasis ICT dalam pelaksanaan Kurikulum 2013 dibantu peneliti
\end{abstract}

Kata Kunci: media pembelajaran; ICT

\begin{abstract}
DEVELOPMENT OF LEARNING MEDIA OF ICT BASED ON SUBTEMA BE GRATEFUL FOR DIVERSITY FOR CLASS IV STUDENTS ELEMENTARY SCHOOL

Abstract. This research is uses development procedures that produce the final product design in the form of developing ICT-based learning media using interactive PowerPoint. This product was developed by researchers combining research steps from Borg and Gall and the ASSURE model. The product developed in this research is ICT-based learning media referring to the 2013 curriculum for fourth grade students of elementary schools. Based on the steps of the development procedure above the researcher only limited to the 5 steps of the development procedure, namely (1) potential and problems, (2) data collection, (3) product design, (4) expert validation, and (5) design revision. This is because the limited time needed in research and ICT-based learning media is made to be a teacher's grip so it is sufficiently validated by four fourth grade elementary school teachers who make ICT-based learning media in the implementation of the 2013 Curriculum aided by researchers
\end{abstract}

Keywords: learning Media; ICT.

\section{PENDAHULUAN}

Perkembangan ilmu pengetahuan dan teknologi menawarkan semakin banyak kemudahan di dalam dunia pendidikan, salah satunya adalah dalam hal penyampaian materi pelajaran kepada peserta didik. Media pembelajaran menurut Novita [1] memegang peranan penting untuk menarik minta siswa dalam belajar. Hal demikian mendorong upaya-upaya pemanfaatan hasil teknologi ke dalam proses belajar mengajar. Salah satunya adalah media pembelajaran berbasis ICT (Information and Communication Technology) sehingga menciptakan suasana penyampaian dan pemahaman materi yang lebih bersemangat dan menyenangkan. Menurut Kudsiyah dan Harmanto [2] Guru perlu mengikuti perkembangan IPTEKS agar mampu meningkatkan mutu pembelajaran.Media ICT dijelaskan dalam jurnal penelitian Suryani [3] bahwa media berupa perangkat keras dan lunak serta aktivitas dalam mengolah data, yang diawali dengan pencarian, pengumpulan, yang selanjutnya diolah, disimpan, kemudian disebar dan pada akhirnya disajikan dalam bentuk informasi dengan bantuan komputer atau perangkat komunikasi lainnya dinamakan dengan media pembelajaran yang berbasis ICT. Hal ini sesuai dengan konsep yang ditkemukakan Susilana dan Riyana [4] Selain itu Muslih [5] mengemukakanp Penggunaan alat-alat bantu atau media pembelajaran dalam dunia pendidikan sudah menjadi keharusan yang mesti ditempuh oleh setiap guru.

Selanjutnya merujuk pada survei kebutuhan salah satu jenis media pembelajaran berbasis ICT adalah Powerpoint interaktif. Meskipun pada hakikatnya Powerpoint interaktif tergolong sebagai salah satu media pembelajaran yang mendorong partisipasi aktif siswa, namun belum banyak tenaga pendidik yang memahami cara mendesain dan menggunakannya di dalam pembelajaran. Secara umum, tenaga pendidik lebih sering mendesain dan menggunakan media pembelajaran konvensional yang hanya menuntut partisipasi aktif satu pihak. Manfaat dari media pembelajaran ICT ini ditemukan pada hasil penelitian Puspitasari [6] yang menemukan bahwa media pembelajaran berbasis ICT memiliki dalam pembelajaran bahasa Indonesia meliputi (1) Menarik perhatian siswa, (2) Pembelajaran menjadi menyenangkan, (3) Pembelajaran menjadi lebih mudah, (4) Memberikan pengetahuan lebih kepada siswa dan (5) Mempermudah komunikasi. 
Meninjau masalah-masalah di atas maka peneliti mengembangkan media pembelajaran berbasis ICT (Powerpoint Interaktif) pada subtema Bersyukur Atas Keberagaman untuk siswa kelas IV (empat) sekolah dasar. Adapun alasan pemilihan subtema Bersyukur Atas Keberagaman adalah karena subtema ini pada hakikatnya memuat lebih banyak aktivitas dan sikap positif yang menuntut patisipasi aktif siswa. Selain itu, pemilihan kelas yakni kelas IV (empat) didasarkan atas alasan bahwa pada zaman ini, siswa kelas atas sudah lebih memahami tentang cara belajar yang menggunakan media bebasis teknologi khususnya Powerpoint interaktif.

\section{METODE PENELITIAN}

Penelitian ini menggunakan jenis penelitian dan pengembangan Research and Development (R\&D). Menggunakan metode ini disebabkan penelitin ini diharapkan yang menurut Sugiyono [7] suatu penelitian yang dapat menghasilkan suatu produk tertentu, dan menguji keefektifan produk tersebut. Dalam upaya menghasilkan produk tersebut, maka diperlukan suatu jenis metode penelitian yang memiliki sifat untuk menganalisis suatu kebutuhan dan dapat diuji keefektifan serta keaktifan produk yang dihsilkan tersebut. Adapun langkah-langkah prosedur pengembangan akan disajikan dalam gambar 1 .

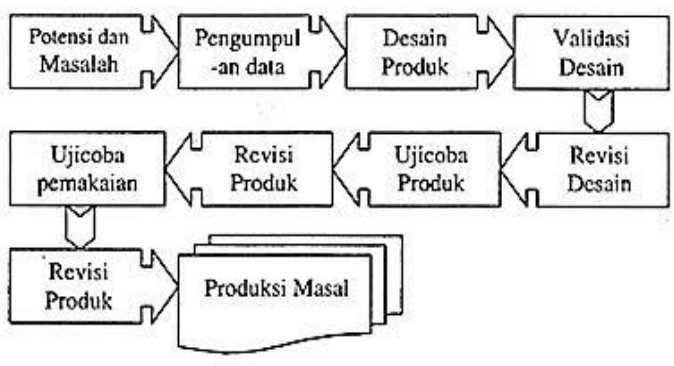

Gambar 1. Bagan Langkah-langkah penggunaan metode (R \& D)

Jenis penelitian ini mengembangkan produk yang berupa media pembelajaran berbasis ICT mengacu kurikulum 2013 untuk siswa kelas IV Sekolah Dasar. Mengacu pada tahapan langkah-langkah prosedur pengembangan seperti dalam bagan di atas, maka dalam penelitian ini akan dibatasi pada lima (5) langkah. Kelima langkah tersebut terdiri dari (1) potensi dan masalah, (2) pengumpulan data, (3) desain produk, (4) validasi ahli, dan (5) revisi desain. Batasan waktu yang diperlukan merupakan salah satu alasan dalam penelitian dan media pembelajaran berbasis ICT ini yang dibuat untuk menjadi pegangan guru, sehingga cukup divalidasi oleh empat guru kelas IV SD yang telah membuat media pembelajaran berbasis ICT dalam pelaksanaan Kurikulum 2013.

\section{Prosedur pengembangan}

Penelitian ini menggunakan prosedur pengembangan yang menghasilkan desain produk final berupa pengembangan media pembelajaran berbasis ICT dengan menggunakan Powerpoint interaktif. Produk ini peneliti kembangkan dengan menggabungkan langkah-langkah penelitian dari Borg and Gall dan model ASSURE.

\section{Instrumen Penelitian}

Penelitian pengembangan ini menggunakan instrumen penelitian berupa daftar pertanyaan wawancara dan kuesioner. Daftar pertanyaan wawancara digunakan untuk menganalisis kebutuhan terhadap media pembelajaran berbasis ICT dengan menggunakan Powerpoint Interaktif untuk siswa kelas IV Sekolah Dasar.

\section{Teknik pengumpulan Data}

Teknik pengumpulan data yang digunakan ini merupakan wawancara dan kuesioner.

a. Wawancara

Wawancara dengan tujuan untuk melakukan survei kebutuhan terkait dengan media pembelajaran berbasis ICT. Peneliti melakukan wawancara kepada guru kelas IV SDN Pengadilan 2 Bogor. Data dianalisis untuk mendapatkan informasi terkait dengan kebutuhan guru untuk media pembelajaran berbasis ICT.

b. Kuesioner

Teknik pengumpulan data berikut ini berupa kuesioner dengan tujuan untuk memvalidasi dan membantu peneliti dalam melakukan revisi atas media pembelajaran berbasis ICT yang telah dibuat. Validasi dengan tujuan untuk mengetahui kekurangan dan kelebihan dari produk yang sudah dibuat oleh peneliti.

\section{Teknik Analisis Data}

Data penelitian ini dianalisis secara kualitatif dan kuantitatif dengan penjelasan sebagai berikut:

a. Data kualitatif

Data kualitatif berupa komentar yang dikemukakan oleh dua guru kelas IV Sekolah Dasar. Data tersebut dianalisis sebagai dasar untuk memperbaiki dan mengetahui kelayakan produk yang dihasilkan.

b. Data kuantitatif

Data berupa skor dari penilaian oleh guru kelas IV Sekolah Dasar. Data yang dianalisis sebagai dasar dari hasil penilaian kuesioner diubah menjadi interval. Skala penilaian terhadap media pembelajaran berbasis ICT yang dikembangkan yaitu sangat baik (4), baik (3), kurang baik (2), sangat kurang baik (1). Perolehan skor dari penilaian validator dihitung dengan menggunakan skala Likert.

Skala pengukuran untuk tingkat kebaikan 1 (sangat kurang baik), 2 (kurang baik), 3 (baik), 4 (sangat baik). Berikut adalah rumus Skala Likert untuk mengetahui interval penilaian skala numerik.

$$
\begin{aligned}
\text { Rumus } & : \mathrm{RS}=(\mathrm{m}-\mathrm{n}) / \mathrm{b} \\
\mathrm{RS} & =(4-1) / 4 \\
\mathrm{RS} & =0,75
\end{aligned}
$$


Tabel 1. Skala Likert

\begin{tabular}{lll}
\hline Sangat & SB & $3,25 \times 4$ \\
Baik & & \\
Baik & B & $2,5 \times<3,25$ \\
Kurang & KB & $1,75 \times<2.5$ \\
Baik & & \\
$\begin{array}{l}\text { Sangat } \\
\text { Kurang }\end{array}$ & SKB & $1 \times 1,75$ \\
Baik & & \\
\hline
\end{tabular}

Dari hasil perhitungan interval di atas kemudian dapat dibuat tabel perhitungan hasil validasi terhadap kualitas media pembelajaran berbasis ICT dengan skala Likert seperti berikut:

Skor : Jumlah total dari masing-masing variabel Rata-rata : Skor penilaian $(\mathrm{SB}=4)+(\mathrm{B}=3)+(\mathrm{KB}=2)+$ $(\mathrm{SKB}=1)$

Hasil dari perhitungan skor masing-masing validasi yang dilakukan akan dicari rata-rata skor perolehannya kemudian dapat dikonversikan dari data kuantitatif ke data kualitatif dalam kategori tertentu seperti yang tertera pada tabel kriteria skor skala empat.

\section{HASIL DAN PEMBAHASAN}

Penelitian pengembangan ini hanya pada tahapan validasi produk, belum pada tahapan ujicoba. Dalam penelitian ini menggunakan beberapa langkah dalam mengembangkan media pembelajaran berbasis ICT mengacu pada kurikulum 2013 . Langkah awal yang dilakukan dalam penelitian ini yaitu membagi tema dan sub tema. Selanjutnya peneliti membuat jaring-jaring pada kompetensi Inti dan kompetensi Dasar. Langkah berikutnya peneliti menentukan indikator dan tujuan pembelajaran sesuai dengan kompetensi Dasar. Langkah berikutnya peneliti merancang RPP berdasarkan indikator dan tujuan pada setiap muatan pembelajaran. Dalam RPP yang dikembangkan peneliti membuat media pembelajaran berbasis ICT. Dalam media pembelajaran berbasis ICT berupa PowerPoint interaktif. PowerPoint interaktif ini dikembangkan setiap pembelajaran dan dalam media PowerPoint interaktif berisi petunjuk dan cara penggunanaan media pembelajaran PowerPoint, motivasi siswa, materi, Lembar Kerja Siswa,Video, Gambar, Soal latihan, dan background yang membuat PowerPoint menjadi menarik.

Peneliti melakukan validasi produk yang dihasilkan berupa pengembangan media pembelajaran berbasis ICT dengan menggunakan Powerpoint interaktif kepada empat orang. Validasi dilakukan oleh dua orang dosen ahli kurikulum 2013 dan media pembelajaran serta dua guru sekolah dasar. Validasi dilakukan untuk mengetahui kualitas dan kelayakan produk yang telah dikembangkan oleh peneliti. Ahli kurikulum 2013 dan media pembelajaran berbasis ICT divalidasi oleh dua dosen yakni Ibu E dan Ibu H, sebanyak satu kali pada tanggal 16 Januari 2019. Aspek yang dinilai dari media pembelajaran berbasis ICT adalah 1) Aspek konten da isi, 2) Aspek tampilan, 3) Aspek penggunaan dan penyajian, 4) Aspek Bahasa. Berdasarkan hasil validasi dari keempat aspek tersebut maka, skor ratarata dari Ibu $\mathrm{E}$ memperoleh skor rata-rata 3,52 termasuk kategori "Sangat Baik" dan skor rata-rata dari Ibu H memperoleh skor rata-rata 3, 59 termasuk kategori "Sangat Baik". Media pembelajaran dinyatakan layak digunakan dengan revisi sesuai saran.

Dari kedua ahli validator kurikulum 2013 memberikan beberapa komentar berisi saran perbaikan untuk aspek tampilan dan penggunaan dan penyajian, pakar validator media pembelajaran ICT memberikan komentar yaitu teks yang digunakan dipersingkat agar lebih dimengerti dengan jelas dan untuk pilihan tombol perlu diperhatikan agar terlihat lebih jelas dan menarik. Media pembelajaran berbasis ICT yang divalidasi oleh kedua dosen kurikulum 2013 dan media pembelajaran direvisi sesuai dengan komentar dan saran. Data validasi secara rinci ada dilampirkan data mentah skor validasi ahli media pembelajaran berbasis ICT. Saran dan revisi tersebut akan dijabarkan dalam tabel berikut:

Tabel 2. Saran dan revisi dari pakar ahli kurikulum 2013

\begin{tabular}{clll}
\hline No & $\begin{array}{c}\text { Aspek yang } \\
\text { dinilai }\end{array}$ & \multicolumn{1}{c}{ Saran } & Perbaikan \\
\hline & \multicolumn{3}{c}{ Aspek tampilan } \\
\hline 1. & $\begin{array}{l}\text { Pemilihan } \\
\text { simbol untuk } \\
\text { tombol perlu } \\
\text { diperhatikan }\end{array}$ & $\begin{array}{l}\text { Simbol untuk } \\
\text { tombol perlu } \\
\text { diganti agar } \\
\text { lebih menarik }\end{array}$ & $\begin{array}{l}\text { Dilakukan } \\
\text { perbaikan } \\
\text { pada bagian } \\
\text { tombol }\end{array}$ \\
\hline 2. & Menu & Untuk petunjuk & Dilakukan \\
& ditampilkan & ditampilkan & petunjuk \\
& sejak awal & sejak awal & tampilan \\
& & sehingga lebih & sejak awal \\
& jelas & \\
\hline 3. & Teks yang & Teks perlu & Dilakukan \\
& digunakan & dipersingkat & perbaikan \\
& terlalu & agar lebih jelas & pada teks \\
& panjang & & \\
\hline
\end{tabular}

\section{Data hasil validasi guru SD Kelas IV pelaksanaan kurikulum 2013.}

Produk media pembelajaran berbasis ICT dengan menggunakan PowertPoint Interaktif juga divalidasi oleh dua orang guru kelas IV pelaksanaan kurikulum 2013. Guru yang menjadi validator yaitu ibu $\mathrm{S}$ dan Ibu E guru kelas IV. Validasi oleh ibu S dilakukan pada tanggal 21 Januari 2019 dan Ibu P dilakukan pada tanggal 28 Januari 2019. Aspek yang dinilai pada media pembelajaran berbasis ICT berupa Powerpoint interaktif, yaitu: 1) Aspek konten dan isi; 2) Aspek tampilan; 3) Aspek penggunaan dan penyajian, 4) Aspek bahasa. Aspek yang dinilai ini memiliki kesamaan dengan penelitian Nursanti, Sugiatno., dan Hartoyo [8].

Berdasarkan hasil validasi oleh guru tersebut, ibu S memberikan skor rata-rata 3,09 dengan kategori "Baik" media pembelajaran dapat dinyatakan layak digunakan tanpa revisi dan hasil validasi oleh Ibu $\mathrm{P}$ memberikan skor ratarata 3,31 dengan kategori "Sangat Baik" dan media pembelajaran ICT dapat dinyatakan layak digunakan di uji coba tanpa revisi. 
Berikut merupakan tabel hasil penelitian dari ahli.

Tabel 3. Rerata Hasil Produk

\begin{tabular}{cccc}
\hline \multirow{2}{*}{ No } & \multirow{2}{*}{ Validator } & \multicolumn{2}{c}{ Media Pembelajaran } \\
\cline { 3 - 4 } & & SCT \\
\hline 1 & Ahli Kurikulum & 3,52 & Kategori \\
2 & Ahli Media & 3,59 & Sangat baik \\
3 & Guru kelas IV & 3,09 & Baik baik \\
4 & Guru kelas IV & 3,31 & Sangat baik \\
\hline \multicolumn{2}{c}{ Jumlah } & 13,51 & \\
\hline $\begin{array}{c}\text { Rerata (jumlah total : } \\
\text { validator) }\end{array}$ & 3,37 & \\
\hline & & \\
\hline & Kategori & & Sangat baik \\
\hline
\end{tabular}

Spesifikasi produk media pembelajaran berbasis ICT berupa Powerpoint interaktif dipaparkan sebagai berikut:

\section{a. Slide pembukaan berisi:}

1) Identitas media, tema, dan subtema.

Tampilan menarik dapat memunculkan motivasi siswa dalam belajar. Maka produk yang dibuat oleh peneliti memberikan tampilan yang menarik.

2) Slide petunjuk media secara umum.

Petunjuk yang menarik akan membuat siswa tidak keliru dalam membuka dan mempelajari tentang materi yang terdapat dalam sebuah slide.

3) Slide petunjuk penggunaan secara detail

4) Dalam sebuah tampilan perlu adanya petunjuk yang jelas sehingga dapat memudahkan siswa dalam belajar. Berdasarkan produk yang dibuat oleh peneliti memberikan sebuah petunjuk yang lebih jelas di bawah ini.

5) Kompetensi Dasar dan Indikator.

b. Slide isi:

1) Slide isi materi : Untuk meningkatkan siswa dallam belajar maka peneliti membuat ringkasan materi yang bisa membuat siswa mudah untuk memahami tentang materiyang diberikan guru. Maka, peneliti membuat ringkasan yang lebih etail seperti contoh yang ada di bawah ini.

2) Slide gambar

Gambar yang menarik dapat menumbuhkan perhatian siswa dalam belajar. Dengan demikian maka peneliti mengambil contoh slide yang berisi gambar.

3) Slide teks bacaan

4) Slide pertanyaan diskusi kelompok

5) Slide video

Dalam tampilan ini terdapat juga video menarik perhatian siswa untuk belajar. Peneliti harapkan agar video ini dapat membantu siswa untuk mengerti tentang materi yang sudah dipelajari.

6) Slide yang berisi soal evaluasi

7) Slide kunci jawaban

\section{c. Slide berisi penutup}

Tampilan refleksi ini dapat menyimpulkan semua keseluruhan tentang palajaran yang berlangsung pada hari itu. Maka peneliti membuat produk ini dengan harapan dapat menarik perhatian siswa untuk mengikuti pelajaran.
Dengan demikian hasil penelitian membuktikan bahwa media pembelajaran ICT dengan menggunakan kurikulum 2013 yang telah divalidasi oleh dua ahli dan 2 guru Sekolah Dasar kelas IV, maka diperoleh data media pembelajaran berbasis ICT ini termasuk dalam kategori "Sangat Baik" dengan skor rerata akhir yaitu 3, 37 hasil tersebut peneliti jabarkan dalam tabel 3. Produk akhir pada media pembelajaran berbasis ICT dikembangkan sesuai dengan spesifikasi produk yang telah dibuat. Sanaky [9] mengatakan bahwa Microsoft Powerpoint adalah program aplikasi presentasi yang merupakan yang salah satu program aplikasi di bawah Microsoft Office program komputer dan tampilan kelayar dengan menggunakan bantuan LCD. Hasil penelitian ini tidak jauh berbeda dengan yang hasil penelitian Miftakhul [10] bahwa pembelajaran dengan media berbasis ICT lebih dapat mengaktifkan siswa , kemudian penelitian Nursanti [8] juga menemukan peningkatan pada hasil belajar menjadi di atas KKM yang ditentukan. Penelitian Kuncahyono, Sudarmiatin [11] juga membuktikan bahwa media berbasis ICT mampu meningkatkan hasil dan minat belajar siswa.

\section{SIMPULAN}

Berdasarkan hasil penelitian dan pembahasan maka dapat disimpulkan sebagai berikut:

1. Penelitian media pembelajaran berbsis information and Communication Technology (ICT) berupa Powepoint interaktif mengacu kurikulum 2013 dikembangkan berdasarkan langkah penelitian pengembangan Berg and Gall dan model ASSURE. Prosedur pengembangan tersebut terdiri dari 5 langkah, yaitu (1) potensi dan masalah, (2) pengumpulan data, (3) desain produk, (4) validasi ahli, (5) revisi desain sampai menghasilkan desain produk final berupa Pengembangan media pembelajaran berbasis ICT (Powerpoint interaktif) Mengacu Kurikulum SD 2013 Pada Subtema Bersyukur atas Keberagaman.

2. Produk media pembelajaran berbasis ICT mengacu kurikulum SD 2013 melalui tahap validasi. Validasi produk dilakukan oleh dua orang pakar media pembelajaran berbasis ICT dan dua orang guru kelas IV sekolah dasar. Aspek yang menjadi kriteria penilaian ketika validasi yaitu (1) aspek konten atau isi, (2) aspek tampilan, (3) aspek penyajian dan penggunaan, (4) aspek bahasa. Data hasil validasi kemudian akan di konversikan dari data kuantitatif ke kualitatif skala empat. Berdasarkan hasil penelitian pengembangan yang telah melalui tahap-tahap pengembangan, antara lain validasi oleh pakar media pembelajaran berbasis ICT dengan menggunakan powerpoint interakif dengan validator Ibu $\mathrm{M}$ mendapatkan skor 3,52 termasuk kategori "Sangat Baik" dan Ibu A mendapatkan skor 3,59 termasuk kategori "Sangat Baik" dan dua guru kelas IV $\mathrm{SD}$, yakni Ibu S dengan mendapatkan skor 3,09 termasuk kategori "Baik" dan Ibu P mendapat skor 3,31 termasuk 
kategori "Sangat Baik". Dari keempat validator tersebut dapat diperoleh rerata skor produk media pembelajaran berbasis ICT yaitu 3,37. Skor tersebut menunjukan bahwa kualitas media pembelajaran berbasis ICT dengan menggunakan powerpoint interaktif yang mengacu kurikulum 2013 subtema Bersyukur atas Keberagaman untuk siswa kelas IV Sekolah Dasar Pengadilan 2 termasuk kategori "Sangat Baik" dan layak digunakan dinilai dari aspek konten atau isi, aspek tampilan, aspek penggunaan dan penyajian, serta aspek bahasa.

\section{REFERENSI}

[1] Novita, Lina. 2015. Pengaruh Penggunaan Multimedia VCD terhadap Motivasi Belajar pada Mata Kuliah Budaya Masyarakat Demokratis. Jurnal Kreatif: Pendidikan, Kebudayaan dan Seni. Volume 18, No.2.

[2] Kudsiyah, Siti, dan Harmanto. 2017. Pengembangan Multimedia Power Point Interaktif Materi Tata Urutan Peraturan Perundang-Undangan Nasional Kelas VIIID SMPN1 Jabon. Jurnal Kajian Moral dan Kewarganegaraan. Volume 05 Nomor 01 Tahun 2017, 1 - 15b Kajian Moral dan Kewarganegaraan. Volume 05 Nomor 01 Tahun 2017, $1-15$.

[3] Suryani, Nunuk. 2016. Pengembangan Media Pembelajaran Sejarah Berbasis IT. Jurnal Sejarah, Budaya dan Pengaarannya. http://journal2.um.ac.id /index.php/sejarah-dan-budaya/article/view/1525 (diakses 10 Juli 2018)

[4] Susilana, R. dan Riyana, Cepi. 2009. Media Pembelajaran Hakikat Pengembangan, Pemanfaatan, dan Penilaian. Bandung: CV. Wacana Prima.

[5] Muslih. 2016. Pemanfaatan Media Pembelajaran Berbasis ICT pada Lembaga Pendidikan NonFormal TPQ. Jurnal Dimas. Volume 12. Nomor 2.

[6] Puspitasari, Septiana Dewi. 2015. Manfaat Media Pembelajaran Berbasis ICT (Information And Communication Technology) Dalam Pembelajaran Bahasa Indonesia. http://download.portalgaruda.org/ article.php? article $=430838 \& \mathrm{val}=$ (diakses $10 \mathrm{Juli}$ 2018)

[7] Sugiyono. 2017. Metode Penelitian Kuantitatif, Kualitatif, dan $R \& D$. Bandung: Alfabeta

[8] Nursanti, Ria., Sugiatno. Hartoyo, Agung. 2015. Pengembangan Media Pembelajaran Berbasis ICT Untuk Meningkatkan Kemampuan Representasi Matematis Siswa Dalam Materi SPLDV. Jurnal Pendidikan dan Pembelajaran. http://jurnal.untan. ac.id/index.php/jpdpb/ article/view/ 10185

[9] Sanaky, H. 2013. Media pembelajaran interaktifinovatif. Buku bacaan wajib guru, dosen, dan calon pendidik. Yogyakarta: Kaukaba Dipantara.

[10] Miftakhul., Nuryanto, Sri., Fawaid, Miftahul. 2010. 9Pengaruh Penggunaan Media Pembelajaran Berbasis ICT (Information,Communication, And Technology) Terhadap Motivasi Belajar Siswa kelas
$X \quad$ Pada Pembelajaran Ekonomi Di SMANI Banguntapan. Pelita-Jurnal Penelitian Mahasiswa. https://journal.uny.ac.id/index.php/pelita/article/view/ 4266.

[11] Kuncahyono, Sudarmiatin. 2018. Pengembangan Multimedia Interaktif Pada Pembelajaran Tematik Indahnya Negeriku Untuk Siswa Kelas IV Sekolah Dasar. Volume 3, No. 2, Desember 2018 Tersedia Online di http://journal2.um.ac.id/index.php/jktpk 